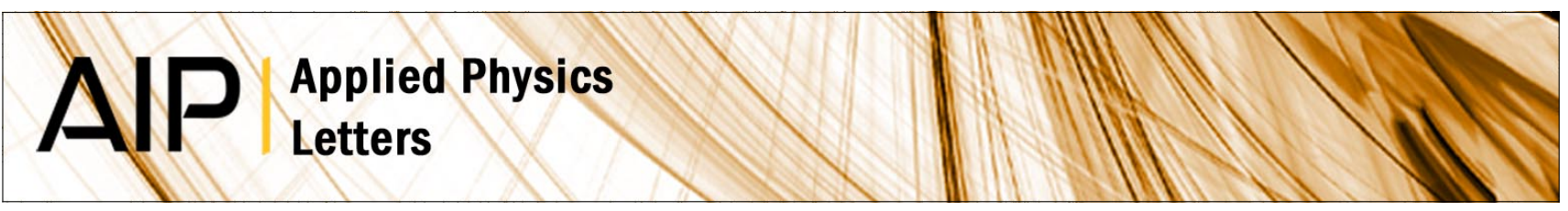

\title{
Tuneable optical lenses from diamond thin films
}

A. Kriele, O. A. Williams, M. Wolfer, D. Brink, W. Müller-Sebert et al.

Citation: Appl. Phys. Lett. 95, 031905 (2009); doi: 10.1063/1.3183534

View online: http://dx.doi.org/10.1063/1.3183534

View Table of Contents: http://apl.aip.org/resource/1/APPLAB/v95/i3

Published by the American Institute of Physics.

\section{Related Articles}

Quantum rod emission coupled to plasmonic lattice resonances: A collective directional source of polarized light Appl. Phys. Lett. 100, 111103 (2012)

Visualization of the conductive channel in a planar resistance switching device based on electrochromic materials

J. Appl. Phys. 111, 053504 (2012)

Whispering gallery mode selection in optical bottle microresonators

Appl. Phys. Lett. 100, 081108 (2012)

Precise real-time polarization measurement of terahertz electromagnetic waves by a spinning electro-optic sensor

Rev. Sci. Instrum. 83, 023104 (2012)

Theoretical description of thermal lens spectrometry in micro space

J. Appl. Phys. 111, 033109 (2012)

\section{Additional information on Appl. Phys. Lett.}

Journal Homepage: http://apl.aip.org/

Journal Information: http://apl.aip.org/about/about_the_journal

Top downloads: http://apl.aip.org/features/most_downloaded

Information for Authors: http://apl.aip.org/authors

\section{ADVERTISEMENT}

\section{(1) ACCELERATE AMBER AND NAMD BY 5X. NVIDIA TRYIT ONAFREE, REMOTELYYHOSTED CLUSTER.}




\title{
Tuneable optical lenses from diamond thin films
}

\author{
A. Kriele, ${ }^{\text {a) }}$ O. A. Williams, M. Wolfer, D. Brink, W. Müller-Sebert, and C. E. Nebel \\ Fraunhofer Institut Angewandte Festkörperphysik, Tullastrasse 72, 79108 Freiburg, Germany
}

(Received 4 June 2009; accepted 27 June 2009; published online 20 July 2009)

\begin{abstract}
Nanocrystalline diamond (NCD) membranes of $150 \mathrm{~nm}$ thickness and diameters in the millimeter range grown by microwave-assisted chemical-vapor deposition were bulged to investigate their mechanical properties and their use as tuneable optical lenses. The NCD films were grown at different $\mathrm{CH}_{4} / \mathrm{H}_{2}$ gas mixtures to vary the $s p^{2} / s p^{3}$ ratio and thereby to tune their mechanical, optical, and surface morphology properties. By applying gas over pressure the membrane forms a lens shaped geometry. From deflection data we calculated Young's moduli which decrease with increasing $\mathrm{CH}_{4} / \mathrm{H}_{2}$ ratio from $1160 \mathrm{GPa}$ at $0.5 \%$ to $900 \mathrm{GPa}$ at $7 \%$. Optical lens applications show a variation in the focal point from infinity to $3.5 \mathrm{~mm}$. The data indicate that NCD is a promising material for tuneable optical lenses applications. (c) 2009 American Institute of Physics.
\end{abstract}

[DOI: $10.1063 / 1.3183534]$

Tuneable micro-optics are currently manufactured almost exclusively from polymers [polydimethylsiloxane (PDMS) and SU8] or silicon. ${ }^{1}$ These materials are, however, limited by their mechanical and tribological properties which make them less than ideal for applications in fast moving microelectromechanical systems (MEMS) devices and in harsh environments where optical transparency is required. Microlenses made of polymer membranes and pneumatically tuned by hydrogels or oils show adverse effects such as swelling of the membrane and no uniformity of the membrane thickness during expansion which causes spherical aberration. ${ }^{2}$ When gas is used for actuation the permeability of such polymer membranes make stable positioning difficult. $^{3}$

Using thin film diamond will overcome these limits as diamond films are known to show exceptional hardness, ${ }^{4}$ wear-resistance, ${ }^{5}$ chemical stability, and high thermal conductivity ${ }^{6}$ in addition to optical transparency from deep UV to far infrared. ${ }^{7-10}$ In this paper we show that diamond thin films are also suitable for tuneable microlens applications which are planned to be implemented in arthroscopic microsurgery devices where biocompatibility, chemical stability, and optical properties are of high importance.

For this application we use nanocrystalline diamond films grown by microwave-assisted chemical-vapor deposition (MWCVD) on silicon substrates. Silicon is partially removed to generate NCD membranes of typically $1-2 \mathrm{~mm}$ in diameter. We show that the shape of NCD membranes can be tuned to lens properties which allow varying of the focal point from infinity to $3.5 \mathrm{~mm}$. These experiments are also applied to characterize Young's moduli as function of the $\mathrm{CH}_{4} / \mathrm{H}_{2}$ gas mixtures during the growth.

NCD films of $150 \mathrm{~nm}$ thickness were grown on $2 \mathrm{in}$. silicon wafers where the silicon surface is ultrasonificated for 30 min with a water based suspension of ultra dispersed (0.1 wt \%) nanodiamond (UDD) particles of typically $5-10 \mathrm{~nm}$ in size. ${ }^{11}$ Then samples were rinsed with de-ionized water and subsequently exposed to MWCVD plasma with $\mathrm{CH}_{4} / \mathrm{H}_{2}$ gas mixtures varying from $0.5 \%, 1 \%, 3 \%, 5 \%$, to $7 \%$ methane in hydrogen at a pressure of 60 mbar using a bell jar reactor. ${ }^{12}$

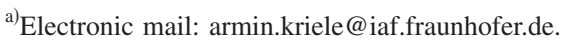

The gas flow rate was 300 SCCM (SCCM denotes standard cubic centimeter per minute). The microwave power was kept constant at $3 \mathrm{~kW}$ and the typical deposition temperature was $800{ }^{\circ} \mathrm{C}$. The deposition time decreases with increasing $\mathrm{CH}_{4}$ admixture and was $30 \mathrm{~min}$ at $0.5 \% \mathrm{CH}_{4}$ and $10 \mathrm{~min}$ at $7 \% \mathrm{CH}_{4}$. The thickness of films was measured in situ using laser interferometry and was proofed by scanning electron microscopy (SEM) cross section images and is in the range of $150 \mathrm{~nm}$.

To remove the silicon substrate we applied photolithographic patterning using $\mathrm{Si}_{3} \mathrm{~N}_{4}$ mask material and $\mathrm{HF}$ and $\mathrm{HNO}_{3}(2: 1)$ wet-chemical etching thereby generating circular membranes from NCD.

By variation in the $\mathrm{CH}_{4} / \mathrm{H}_{2}$ gas mixture during growth, the $s p^{3}$ (diamond) to $s p^{2}$ (graphite) ratio has been varied. In order to investigate the compositional properties of the nanocrystalline diamond films, Raman scattering experiments have been applied. The Raman spectra recorded at an excitation wavelength of $457.94 \mathrm{~nm}$ are shown in Fig. 1(a). The NCD films show peaks at $1332 \mathrm{~cm}^{-1}$, which corresponds to $s p^{3}$-bonded carbon (diamond). The $D$ band at $1350 \mathrm{~cm}^{-1}$ causes broadening of the diamond peak with increasing $\mathrm{CH}_{4}$ admixture. There is a substantial graphite band ( $G$ band) at $1558 \mathrm{~cm}^{-1}$, which corresponds to $s p^{2}$-bonded carbon and two transpolyacetylene bands at $1150 \mathrm{~cm}^{-1}$ and at $1460 \mathrm{~cm}^{-1}$. Both nondiamond bands increase significantly with increasing $\mathrm{CH}_{4}$ content during the growth step. By increasing the $\mathrm{CH}_{4}$ gas admixture from $0.5 \%$ to $7 \%$ the graphite and transpolyacetylene contents rise, as shown in Fig. 1(b). Please note that the values of nondiamond contents were calculated by integration of the area beneath the fitted peaks, as shown in Fig. 1(c).

The surface morphology of the films was measured by atomic force microscopy (AFM) and SEM as depicted in the insets in Fig. 1(d). The grain structure decreases with increasing $\mathrm{CH}_{4}$ admixture and hence the surface roughness rms decreases from $9 \mathrm{~nm}$ at $0.5 \% \mathrm{CH}_{4}$ to $5 \mathrm{~nm}$ at $7 \% \mathrm{CH}_{4}$.

To characterize the mechanical properties of these films bulging experiments have been carried out by applying nitrogen gas pressure on one side of the membrane. The maximum height of deflection [Fig. 2(d)] as a function of applied pressure was measured with a white light interferometer 

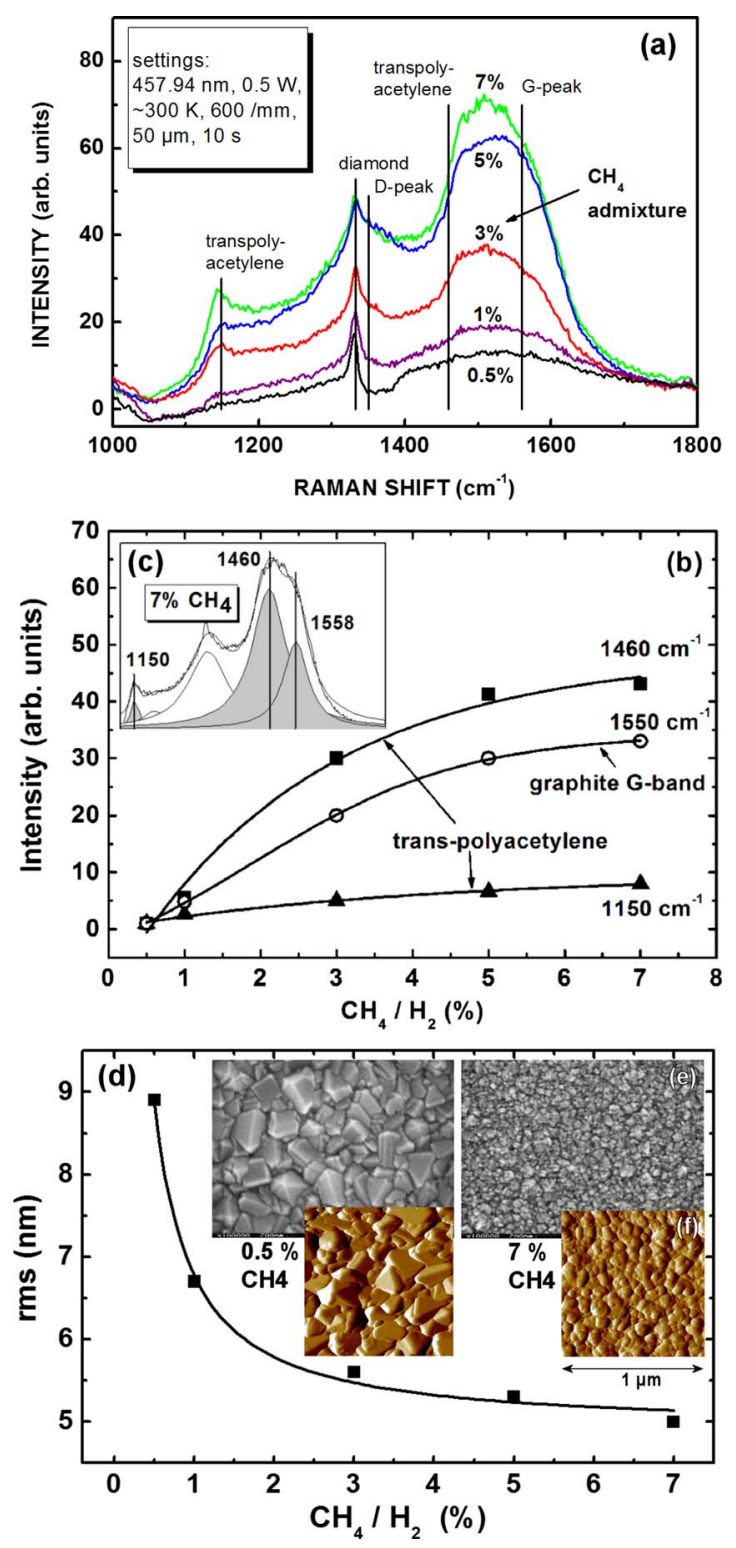

FIG. 1. (Color online) (a) Raman spectra of $150 \mathrm{~nm}$ thin NCD films grown at various $\mathrm{CH}_{4}$ admixtures. (b) Increase in the graphite and transpolyacetylene content within the NCD films calculated from the peak areas. (c) Calculation of nondiamond contents by integration of the fitted Raman peaks. (d) Surface roughness (rms) measured by AFM for NCD films $150 \mathrm{~nm}$ in thickness grown at various $\mathrm{CH}_{4}$ content. (e) $\mathrm{SEM}$ micrographs and (f) $\mathrm{AFM}$ micrographs of films grown at $0.5 \%$ and $7 \% \mathrm{CH}_{4}$ admixture.

(WLI). Results are shown in Fig. 2(a). The load-deflection dynamics of the membranes show extreme flexibility. Membranes $2.5 \mathrm{~mm}$ in diameter and grown at $5 \% \mathrm{CH}_{4}$ admixture expand 60-70 $\mu \mathrm{m}$ before destruction at a critical pressure, which is decreasing with increasing $\mathrm{CH}_{4} / \mathrm{H}_{2}$ ratio. Please note that the membranes do not show any hysteresis or degradation up to 30 cycles, as we have proofed so far. Leak tests on inflated membranes show that there is no pressure drop within $48 \mathrm{~h}$. A stable positioning of these membranes for a long time is therefore possible actuated either with gas or liquids. Proofed by SEM, we did not observe any detachment of the NCD films also when expanding them until they burst which indicates a strong adhesion of the films to the silicon.

We use the bulging variation to calculate the Young's modulus of the NCD films. As the membrane deflection $z$ is
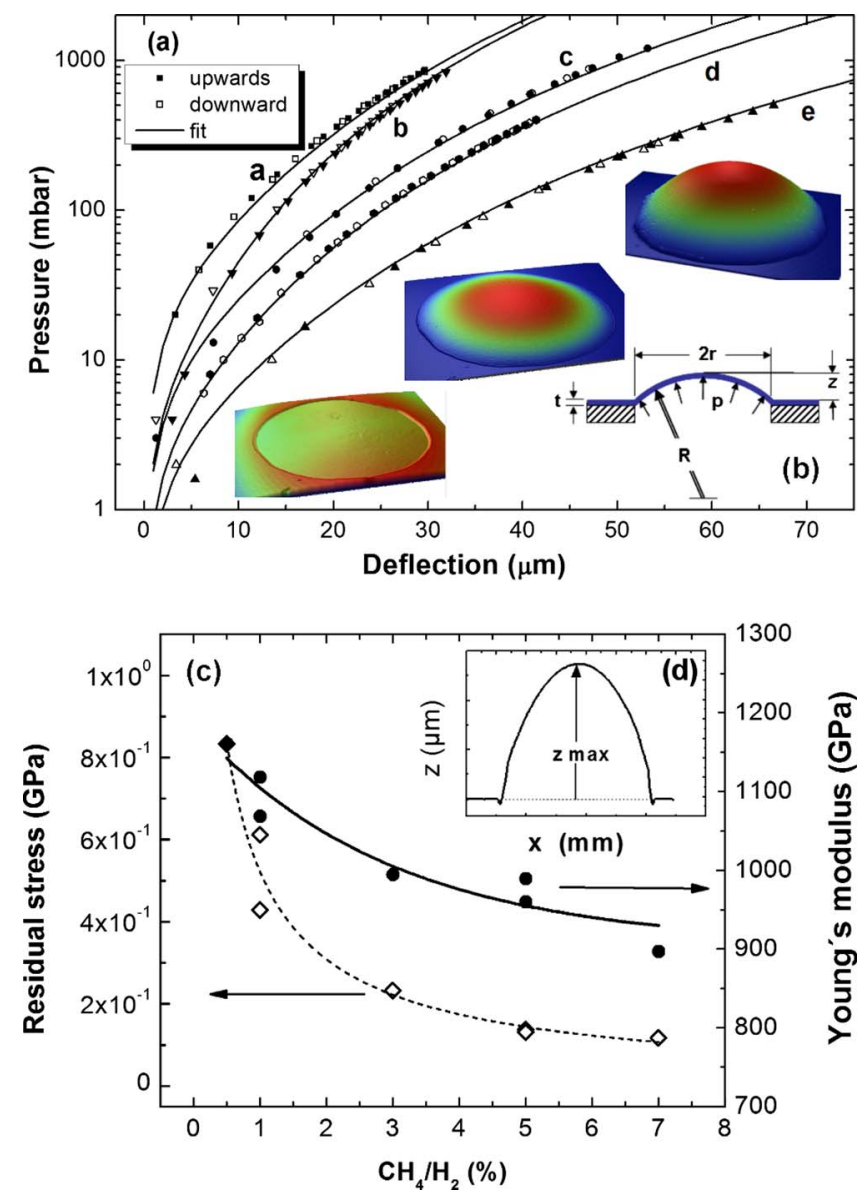

FIG. 2. (Color online) (a) Bulge results at $150 \mathrm{~nm}$ thick NCD membranes with various diameter and grown at various methane admixture a: $1.3 \mathrm{~mm}$, $1 \%$; b: $1.3 \mathrm{~mm}, 5 \%$; c: $1.8 \mathrm{~mm}, 3 \%$; d: $1.9 \mathrm{~mm}, 7 \%$; and e: $2.5 \mathrm{~mm}, 5 \%$ $\mathrm{CH}_{4}$. (c) Residual stress and Young's modulus calculated from the fit curves out of (a). (d) Cross section through maximum deflection of a bulged membrane measured by WLI.

hemispherical in shape we can apply the following equation: ${ }^{13,14}$

$$
p=\frac{c_{1} t}{r^{2}} \sigma_{0} z+\frac{c_{2} f(\nu)}{r^{4}} \frac{E}{1-\nu} z^{3},
$$

where $p$ is the uniform pressure applied to the membrane, $z$ is the maximum deflection measured at the center of the membrane, $r$ is the membrane radius, $t$ is the membrane thickness [Fig. 2(b)], $\sigma_{0}$ is the residual stress, $E$ is the Young's modulus, and $\nu$ is the Poisson's ratio $(0.069) .{ }^{15}$ The geometrical coefficients $c_{1}, c_{2}$, and $f(\nu)$ for circular membranes are $4,2.67$, and 1 respectively. ${ }^{12}$ The residual stress $\left(\sigma_{0}\right)$ and Young's moduli $(E)$ have been calculated by fitting this equation to the experimental data. As result, the Young's moduli varies from $E=1160,1070,995,960$, to $897 \mathrm{GPa}$ while the residual stress drops from $\sigma_{0}=0.83,0.51,0.23$, 0.13 , to $0.11 \mathrm{GPa}$ for $\mathrm{CH}_{4}$ in $\mathrm{H}_{2}$ varying from $0.5 \%, 1 \%, 3 \%$, $5 \%$, and $7 \%$, respectively, as shown in Fig. 2(c). Please note that the Young's modulus of $\mathrm{NCD}$ grown at low $\mathrm{CH}_{4}$ content is only slightly smaller than that of single crystalline diamond (1220 GPa). Due to these unique properties of NCD only thin membranes are required to achieve such large deflections while polymer films require $10 \mu \mathrm{m}$ (SU8) to $100 \mu \mathrm{m}$ (PDMS) in thickness for comparable deflection. ${ }^{2}$ 

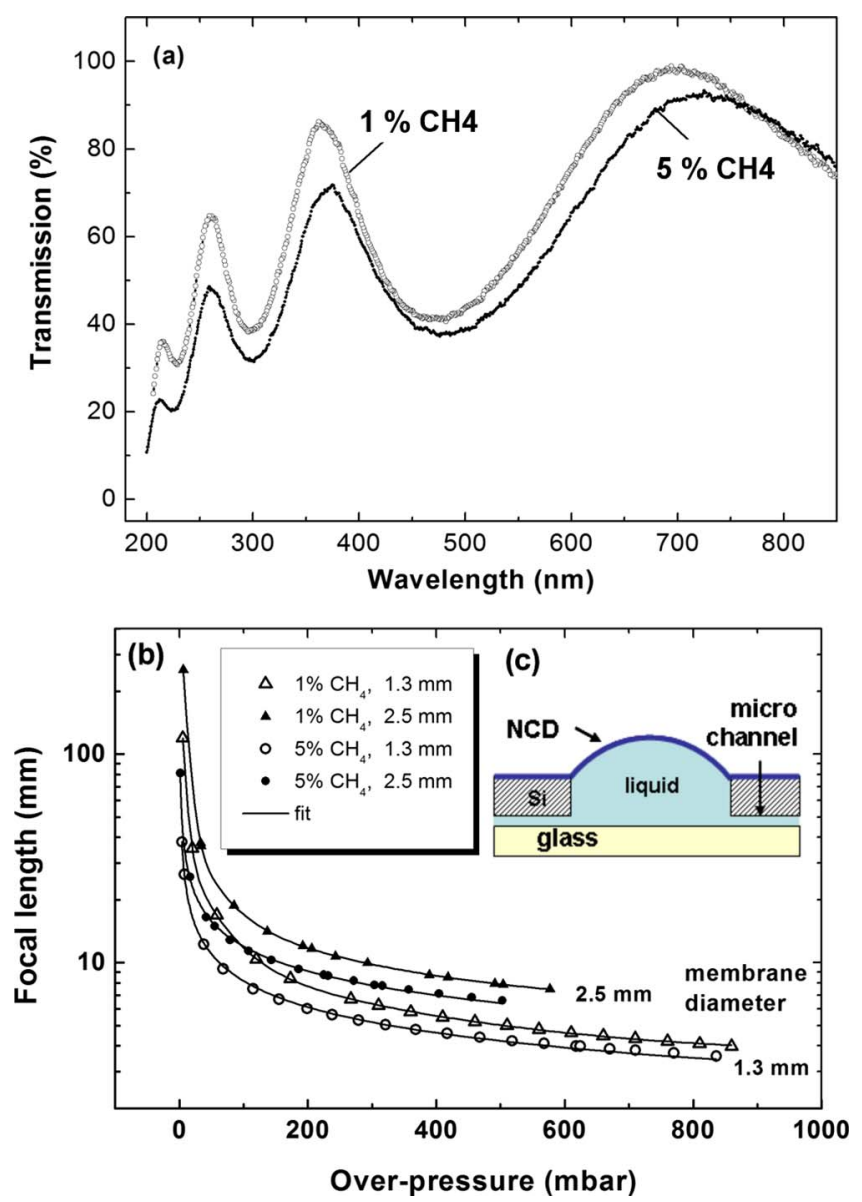

FIG. 3. (Color online) (a) Optical transmission through $150 \mathrm{~nm}$ thin NCD membranes grown at $1 \%$ and $5 \% \mathrm{CH}_{4}$ admixture. (b) Focal length for membranes 1.3 and $2.5 \mathrm{~mm}$ in diameter grown at $1 \%$ and $5 \% \mathrm{CH}_{4}$ admixture. (c) Scheme of a pressure tuned membrane lens.

The optical properties of the NCD membranes were characterized measuring transmission properties in the regime 200-850 nm [Fig. 3(a)]. The transmission is dominated by interference effects and varies from $20 \%$ at $200 \mathrm{~nm}$ to $80 \%$ at $700 \mathrm{~nm}$. The transmission properties are only slightly affected by the increasing $s p^{2}$ content.

From these membranes, microlenses have been fabricated by sealing the backside with a thin glass slide and supporting the circular cavity with liquids through microchannels [Fig. 3(c)]. Using microscope immersion oil as pressure-transmitting liquid which has a refractive index of $n=1.46$ the focal length of such planoconvex lenses can be adjusted over a wide range. It varies from infinity (flat membrane) to $7.5 \mathrm{~mm}$ for lenses of $2.5 \mathrm{~mm}$ in diameter and to 3.5 $\mathrm{mm}$ for lenses of $1.3 \mathrm{~mm}$ in diameter, as shown in Fig. 3(b).

In conclusion, thin nanocrystalline diamond films have been characterized for applications as tuneable optical lenses. Circular NCD membranes of $150 \mathrm{~nm}$ thickness show bulging properties which resemble lens shapes. The bulging variation has been measured as a function of $s p^{2} / s p^{3}$ ratio of films which was tuned by increasing the $\mathrm{CH}_{4}$ admixture to $\mathrm{H}_{2}$ during the CVD growth. The resulting load-deflection membrane properties show up to $70 \mu \mathrm{m}$ deflection of the membranes. They reveal extreme flexibility with no degradation. From variations in the surface expansion as a function of pressure the calculated Young's moduli of NCD films varies from 1160 to $897 \mathrm{GPa}$ by increasing the $\mathrm{CH}_{4} / \mathrm{H}_{2}$ ratio from $0.5 \%$ to $7 \%$. NCD diamond films can be grown very homogeneously on 3 in. wafers on various materials such as silicon, metals, or sapphire. Therefore, this NCD material can be implemented in silicon MEMS technology for hybrid material combinations. The discussed data are promising to apply NCD films for demanding applications such as tuneable lenses where optical transparency, hardness, chemical stability, and biocompatibility are required.

${ }^{1}$ C. Friese, A. Werber, F. Krogmann, W. Mönch, and H. Zappe, IEEJ Trans. Electr. Electron. Eng. 2, 232 (2007).

${ }^{2}$ N. Chronis, G. L. Liu, K. H. Jeong, and L. P. Lee, Opt. Express 11, 19 (2003).

${ }^{3}$ A. Werber and H. Zappe, J. Micro/Nanolith. MEMS MOEMS 17, 1218 (2008).

${ }^{4}$ K. E. Spear and J. P. Dismukes, Synthetic Diamond: Emerging CVD Science and Technology (Wiley, New York, 1994).

${ }^{5}$ F. Piazza, D. Grambole, D. Schneider, C. Casiraghi, A. C. Ferrari, and J. Robertson, Diamond Relat. Mater. 14, 994 (2005).

${ }^{6}$ A. Harkonen, S. Suomalainen, E. Saarinen, L. Orsila, R. Koskinen, O. Okhotnikov, S. Calvez, and M. Dawson, Electron. Lett. 42, 693 (2006).

${ }^{7}$ Y. D. Kim, W. Choi, H. Wakimoto, S. Usami, H. Tomokage, and T. Ando, Appl. Phys. Lett. 75, 3219 (1999).

${ }^{8}$ Y. Zhao, B. Zhang, N. Yao, G. Sun, and J. Li, Diamond Relat. Mater. 16, 650 (2007).

${ }^{9}$ S. T. Patton and B. Bhushan, IEEE Trans. Magn. 34, 575 (1998).

${ }^{10}$ W. I. Urruchi, M. Massi, H. S. Maciel, C. Otani, and L. N. Nishioka, Diamond Relat. Mater. 9, 68 (2000).

${ }^{11}$ O. A. Williams, Chem. Phys. Lett. 445, 255 (2007).

${ }^{12}$ M. Füner, C. Wild, and P. Koidl, Appl. Phys. Lett. 72, 1149 (1998).

${ }^{13} \mathrm{~S}$. Timoshenko and S. Woinowsky-Krieger, Theory of Plates and Shells (McGraw-Hill, New York, 1959).

${ }^{14}$ J. Y. Pan, P. Lin, and F. Maseeh, Proceedings of the Technical Digest IEEE Solid-State Sensors Workshop, 1990 (unpublished), pp. 70-73.

${ }^{15}$ J. E. Field, in Properties and Growth of Diamond, EMIS Datareview Series 9, edited by G. Davies (INSPEC Publication, 1994), p. 36. 